\title{
Characteristics of reoffending accommodation sites in Europe with clusters of Legionnaires' disease, 2003-2007
}

K D Ricketts (kate.ricketts@hpa.org.uk) ${ }^{1}$, R Yadav ${ }^{1}$, M C Rota ${ }^{2}$, C A Joseph ${ }^{1}$, on behalf of the European Working Group for Legionella Infections ${ }^{3}$

1. Respiratory Diseases Department, Health Protection Agency, Centre for Infections, London, United Kingdom

2. Centro Nazionale di Epidemiologia, Sorveglianza e Promozione della Salute, Istituto Superiore di Sanità (National Centre for Epidemiology, Surveillance and Health Promotion, National Institute of Health), Rome, Italy

3. www.ewgli.org

Citation style for this article:

Ricketts KD, Yadav R, Rota MC, Joseph CA, on behalf of the European Working Group for Legionella Infections. Characteristics of reoffending accommodation sites in Europe with clusters of Legionnaires' disease, 2003-2007. Euro Surveill. 2010;15(40):pii=19680. Available online: http://www.eurosurveillance.org/ViewArticle. aspx?Articleld $=19680$

Article published on 7 October 2010

Between 2003 and 2007, 21\% ( $=100 / 477)$ of accommodation sites linked to clusters of two or more cases of Legionnaires' disease that were investigated by the European Surveillance Scheme for Travel-Associated Legionnaires' Disease (EWGLINET) went on to be associated with at least one further case, despite reporting that satisfactory control measures had been implemented at the time the cluster was first detected. This paper examines these sites (termed reoffenders) in order to determine whether they share any characteristics that may have contributed to the reoffence. All investigations conducted at cluster sites between 2003 and 2007 were included in the analysis, giving a total of 615 investigations conducted at 477 sites. Every country that investigated more than three cluster sites had to deal with at least one reoffence, and one site reoffended five times. The cases involved in the cluster that stayed elsewhere during their incubation periods could be used to help assess the probability of exposure, and therefore the risk, posed by particular cluster sites. A more extensive investigation and control regime may be needed in some instances to better control the risk of Legionnaires' disease at an accommodation site.

\section{Introduction}

Legionnaires' disease is an atypical pneumonic illness caused by inhalation of aerosolised water droplets containing Legionella spp. bacteria. The disease has an incubation period of two to 10 days and a case fatality rate of approximately $12 \%$ [1]. The bacteria live naturally in the aquatic environment, and can cause outbreaks of disease if water systems become colonised. Stagnation, warm temperatures and the presence of nutrients can all lead to increased bacterial growth and replication. Hotels and other public accommodation sites are particularly associated with the risk of Legionnaires' disease because their water systems often include a large number of outlets (such as showers and washbasins). These outlets should all be flushed through at regular intervals to ensure there is no build-up of bacteria in the pipework. However, if a room is left unoccupied the flushing will depend upon routine control and maintenance procedures at the accommodation site, and there is therefore a risk that the water in the system may be allowed to stagnate [2]. In addition, there may often be long lengths of pipework and it can be difficult to ensure that water temperatures are maintained at a high enough level throughout the building to control bacterial numbers.

The European Legionnaires' Disease Surveillance Network (ELDSNet), formerly known as the European Surveillance Scheme for Travel-Associated Legionnaires' Disease (EWGLINET), collects information on cases of Legionnaires' disease in European residents who have stayed at a public accommodation site in the two to 10 days before the onset of symptoms [3]. If two or more cases of Legionnaires' disease are associated with the same accommodation site within two years, a cluster is formed. In response to each cluster, the country of infection is required to conduct an environmental investigation that meets with the standards required by European guidelines for the control and prevention of travel-associated Legionnaires' disease [4]. A risk assessment must be conducted and control measures initiated within two weeks, resulting in a so-called Form $A$ report. Within a further four weeks (six weeks in total) these control measures should have been completed and environmental sampling for Legionella spp. carried out, resulting in a second report, a Form B report. If either of these reports is not submitted on time or if the investigations are inadequate, there are sanctions that can be applied; the name of the accommodation site is published on the ELDSNet website (formerly the EWGLI website), often resulting in the withdrawal of tour-operators.

In 2003, 632 travel-associated cases were notified to EWGLINET, and a total of 89 new clusters were identified [5-6]. In comparison, 946 travel-associated cases 
were notified to EWGLINET in 2007, and a total of 112 new clusters were identified [7].

Some sites that have been investigated to the standards required in the European guidelines are later associated with further cases. This paper examines these 'reoffending' sites in order to determine whether they share any characteristics that may have contributed to the reoffence.

The European guidelines for the control and prevention of travel-associated Legionnaires' disease were introduced in July 2002 [4]. As the first six months were considered to be an acclimatisation period, this paper addresses accommodation sites with clusters of cases with symptom onset from 2003 to 2007 .

\section{Methods}

All investigations conducted in accordance with the European guidelines at accommodation sites with clusters of cases between 2003 and 2007 were included in the analysis. Some sites appeared more than once in the dataset, representing either reoffences or the onset of new clusters at the site (if there is a period of more than two years between a cluster and a subsequent case, the case is classified as a single case and the site reverts to a non-cluster status).

Following each investigation, a Form B containing summary information is returned by the country to the ELDSNET coordinating centre in Stockholm, Sweden (formerly the EWGLINET coordinating centre in London, United Kingdom). This form includes information on the sampling results at the accommodation site and the control measures applied. The number of rooms available at each of the sites was found using Internet search engines.

Between 2003 and 2007, 615 investigations were conducted at 477 sites. The dataset of all the sites was linked with that of all the investigations to obtain data on mean length of stay, cluster size and whether travel to other sites occurred. The covariates of interest were the country of the site, year of cluster and any reoffence, type of accommodation and number of rooms at the accommodation site, time between previous investigation and reoffence, length of time the case stayed at the site, results of environmental sampling, and the likelihood of the site being the source of infection (whether the cases involved in the cluster used other sites as well). Variables were considered for inclusion as covariates in a logistic regression model if either the chi-square $p$ value or Fisher's exact test $p$ value (as applicable) was less than 0.10 .

\section{Results}

A total of 477 accommodation sites in Europe with clusters of cases of Legionnaires' disease were investigated during 2003 to 2007 . Of these, 377 (79\%) did not reoffend, leaving 100 sites that were associated with subsequent cases within two years of the first investigation. Of the reoffenders, 75 sites reoffended once, 16 reoffended twice (in France $(n=3)$, Greece $(n=3)$, Italy $(n=5)$, Malta $(n=2)$, Turkey $(n=5))$, six sites reoffended three times (in France $(n=3)$, Italy $(n=3)$, Poland $(n=1)$, Turkey $(n=1)$ ), two sites reoffended four times (in Bulgaria and Turkey), and one site reoffended five times (in Turkey). This involved 238 investigations that were conducted at these reoffending sites (100 original investigations and 138 reoffence investigations), giving a total of 615 investigations (Figure).

The countries associated with the cluster sites and investigations included in this analysis are shown in Table 1 . While Italy conducted the most investigations $(n=194)$, only $24 \%$ of these $(n=47)$ were initiated as a response to reoffences. In contrast, 34 of Turkey's 102 investigations (33\%) were as a result of reoffences.

The overall percentage of investigations associated with reoffending sites increased over time from $10 \%$ in 2003 to $28 \%$ in 2007 (Table 2). The proportion of Italian sites reoffending increased in 2006 and 2007, the proportion of French sites reoffending dropped markedly in 2007, while the proportion of Spanish sites reoffending in 2007 rose dramatically. The proportion of Turkish sites reoffending fell in 2006 and 2007, but remained high.

The most common type of accommodation site in the study were hotels $(n=393,88 \%)$, however holiday apartments were slightly more likely to reoffend ( $24 \%$ of apartments reoffended compared with $22 \%$ of hotels). None of the more unusual types of accommodation

\section{FIGURE}

Flow chart showing number of sites and investigations included in dataset

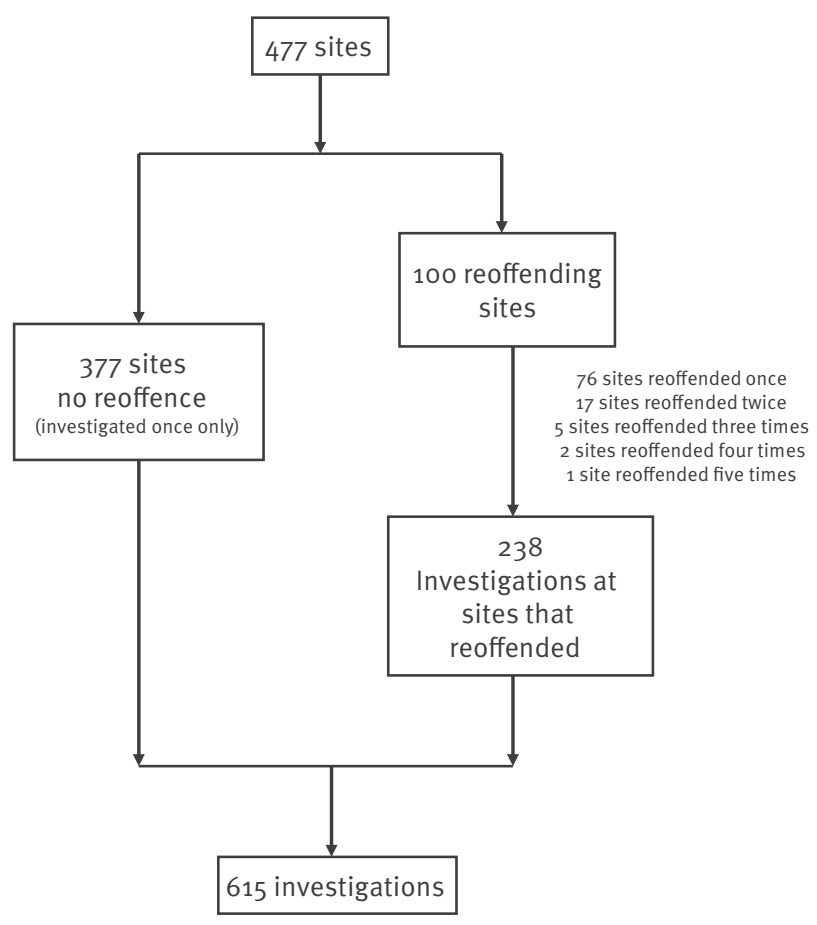


(classified as 'other', such as ships, university halls of residence and truck stops) reoffended during the study period (Table 3 ). The accommodation sites most likely to be associated with reoffences were those with 200-299 rooms: $33 \%(n=18)$ of these sites reoffended at least once during 2003 to 2007 (Table 3). None of these results were statistically significant.

Of the 615 investigations analysed in this study, 355 $(57.7 \%)$ gave water samples that tested positive for Legionella spp., $245(39.8 \%)$ were negative and 15 had unknown results $(2.4 \%)$. Most of the investigations with unknown results were conducted towards the beginning of the study, when Form Bs were not always completed as fully as they were towards the end of the study. Of those investigations that had a known sampling result, the proportion that were positive did not change over time (2003: 55.2\%, 2004: 58.7\%, 2005: $57.6 \%, 2006: 68.1 \%, 2007: 54.7 \%)$. Of the 355 positive sites, $69(19.4 \%)$ went on to be associated with further cases. In comparison, 66 of the $245(26.9 \%)$ negative sites reoffended, suggesting that sites with negative sampling results are more likely to reoffend than those with positive results (chi-square test value: 4.26 , $p=0.039$ ). Three of the remaining sites also reoffended (from those that had unknown sampling results).

The median time to reoffence (the time between investigation and onset of a further case of Legionnaires' disease) by country ranged from 65 days (England and Wales) to 408 days (Germany). A total of 32 cases that initiated the reoffence stayed at the accommodation site in question only one night, 62 stayed between two and seven nights, 42 stayed between eight and 14 nights, and two cases stayed for longer.

The most recent sampling result at each site before the reoffence was extracted. (Six sites were excluded from

\section{TABLE 1}

European countries with accommodation sites, including reoffending sites, investigated following clusters of Legionnaires' disease cases, 2003-2007

\begin{tabular}{|c|c|c|c|c|c|c|}
\hline \multirow[b]{2}{*}{ Country } & \multicolumn{3}{|c|}{ Accommodation sites } & \multicolumn{3}{|c|}{ Investigations conducted } \\
\hline & $\begin{array}{r}\text { Total number of } \\
\text { sites investigated }\end{array}$ & $\begin{array}{r}\text { Number of } \\
\text { reoffending sites }\end{array}$ & $\begin{array}{r}\text { Percentage of } \\
\text { reoffenders }\end{array}$ & $\begin{array}{r}\text { Total number of } \\
\text { investigations }\end{array}$ & $\begin{array}{r}\text { Number of repeat } \\
\text { investigations }\end{array}$ & $\begin{array}{r}\text { Percentage } \\
\text { of repeat } \\
\text { investigations }\end{array}$ \\
\hline Austria & 3 & 1 & 33 & 4 & 1 & 25 \\
\hline Belgium & 1 & 0 & o & 1 & 0 & 0 \\
\hline Bulgaria & 6 & 2 & 33 & 11 & 5 & 45 \\
\hline Croatia & 1 & 0 & 0 & 1 & 0 & 0 \\
\hline Cyprus & 2 & 0 & 0 & 2 & 0 & 0 \\
\hline Czech Republic & 3 & 1 & 33 & 4 & 1 & 25 \\
\hline Denmark & 1 & 0 & 0 & 1 & 0 & 0 \\
\hline England and Wales ${ }^{b}$ & 11 & 1 & 9 & 12 & 1 & 8 \\
\hline France & 100 & 15 & 15 & 118 & 18 & 15 \\
\hline Germany & 12 & 1 & 8 & 13 & 1 & 8 \\
\hline Greece & 25 & 5 & 20 & 33 & 8 & 24 \\
\hline Italy & 147 & 36 & 24 & 194 & 47 & 24 \\
\hline Latvia & 1 & 1 & 100 & 2 & 1 & 50 \\
\hline Luxembourg & 1 & 0 & 0 & 1 & 0 & 0 \\
\hline Malta & 10 & 2 & 20 & 14 & 4 & 29 \\
\hline Netherlands & 3 & 0 & 0 & 3 & 0 & 0 \\
\hline Poland & 3 & 1 & 33 & 6 & 3 & 50 \\
\hline Portugal & 7 & 1 & 14 & 8 & 1 & 13 \\
\hline Russia & 2 & 0 & 0 & 2 & 0 & 0 \\
\hline Scotlandb & 1 & 0 & 0 & 1 & 0 & 0 \\
\hline Spain & 59 & 13 & 22 & 72 & 13 & 18 \\
\hline Sweden & 2 & 0 & 0 & 2 & 0 & 0 \\
\hline Turkey & 68 & 20 & 29 & 102 & 34 & 33 \\
\hline Total & 469 & 100 & 21 & 607 & 138 & 22 \\
\hline Ship ${ }^{c}$ & 8 & 0 & 0 & 8 & 0 & 0 \\
\hline Total & 477 & 100 & 21 & 615 & 138 & 22 \\
\hline
\end{tabular}

a Accommodation sites in the European Surveillance Scheme for Travel-Associated Legionnaires' Disease (EWGLINET) scheme.

b England and Wales (together) and Scotland are independently responsible for the investigation of clusters in their respective countries. Scotland is therefore listed separately in this table.

This category mostly comprises cruise ships, where individuals have slept in cabins onboard. 
this portion of the analysis because the results were not available.) Of the 69 sites that previously tested positive, 41 remained positive following the reoffence, while 26 tested negative (two sites had unknown results). Of the 66 sites that previously tested negative, 35 were also negative during the reinvestigation while 30 tested positive (one had unknown results). Of the three sites with unknown results on previous sampling, one tested positive and two tested negative on reoffence (Table 4 ).

All cases involved in each cluster up to and including the reoffence were analysed to determine if they had also visited other accommodation sites during their 2-10 day incubation period. In 66 of the 138 reoffending sites (excluding six sites as above), the cases had not stayed elsewhere. Of these 66 sites, 52 identified Legionella spp. in the water system either during the original investigation or during the reinvestigation (or both). In 41 reoffending sites, the cases involved in the cluster were a mixture of those who had stayed at that site only and those who had also stayed elsewhere. Legionella spp. were identified in the water system of 31 of these 41 sites. For the remaining 25 reoffending sites, all of the cases involved had visited other sites during their incubation period. Only 14 of these sites returned positive sampling results (Table 4 ). These results were not statistically significant.

\section{Discussion}

Between 2003 and 2007, 21\% $(n=100 / 477)$ of accommodation sites investigated by EWGLINET and reported as having implemented satisfactory control measures went on to be associated with at least one further case of travel-associated Legionnaires' disease within two years. Every country that investigated more than three cluster sites had to deal with at least one reoffence. In contrast, none of the eight clusters located on ships led to reoffences. It is possible that the more unusual cluster sites may be investigated more thoroughly and therefore are less likely to reoffend.

\section{TABLE 2}

Investigations conducted into European accommodation sites, including reoffending sites, with clusters of Legionnaires' disease cases, by year, $2003-2007^{\mathrm{a}}(\mathrm{n}=615)$

\begin{tabular}{|c|c|c|c|c|c|c|}
\hline \multirow{2}{*}{ Country } & \multicolumn{6}{|c|}{ Number of investigations (percentage of reoffences) } \\
\hline & 2003 & 2004 & 2005 & 2006 & 2007 & Total \\
\hline Austria & 0 & $2(0)$ & 0 & $1(0)$ & $1(100)$ & $4(25)$ \\
\hline Belgium & 0 & o & 0 & o & $1(0)$ & $1(0)$ \\
\hline Bulgaria & $4(50)$ & $2(50)$ & 0 & $3(67)$ & $2(0)$ & $11(45)$ \\
\hline Croatia & 0 & 0 & o & $1(0)$ & 0 & $1(0)$ \\
\hline Cyprus & $1(0)$ & o & $1(0)$ & 0 & 0 & $2(0)$ \\
\hline Czech Republic & 0 & 0 & $1(0)$ & $1(0)$ & $2(50)$ & $4(25)$ \\
\hline Denmark & 0 & 0 & 0 & $1(0)$ & 0 & $1(0)$ \\
\hline England and Wales ${ }^{b}$ & $4(0)$ & $1(0)$ & $2(0)$ & $4(25)$ & $1(0)$ & $12(8)$ \\
\hline France & $22(5)$ & $24(25)$ & $20(15)$ & $29(21)$ & $23(9)$ & $118(15)$ \\
\hline Germany & $1(0)$ & $2(0)$ & $2(0)$ & $5(0)$ & $3(33)$ & $13(8)$ \\
\hline Greece & $7(0)$ & $4(50)$ & $10(20)$ & $8(50)$ & $4(0)$ & $33(24)$ \\
\hline Italy & $21(10)$ & $22(23)$ & $38(13)$ & $46(30)$ & $67(31)$ & $194(24)$ \\
\hline Latvia & 0 & 0 & 0 & $1(0)$ & $1(100)$ & $2(50)$ \\
\hline Luxembourg & 0 & 0 & 0 & $1(0)$ & 0 & $1(0)$ \\
\hline Malta & $3(0)$ & $6(33)$ & $1(100)$ & $2(50)$ & $2(0)$ & $14(29)$ \\
\hline Netherlands & 0 & $1(0)$ & 0 & $2(0)$ & 0 & $3(0)$ \\
\hline Poland & 0 & $1(0)$ & $2(100)$ & $3(33)$ & o & $6(50)$ \\
\hline Portugal & 0 & $4(0)$ & 0 & 0 & $4(25)$ & $8(13)$ \\
\hline Russia & 0 & $1(0)$ & 0 & 0 & $1(0)$ & $2(0)$ \\
\hline Scotlandb & 0 & 0 & 0 & 0 & $1(0)$ & $1(0)$ \\
\hline Spain & $12(8)$ & $9(0)$ & $11(27)$ & $25(4)$ & $15(53)$ & $72(18)$ \\
\hline Sweden & 0 & 0 & 0 & $2(0)$ & 0 & $2(0)$ \\
\hline Turkey & $26(15)$ & $15(33)$ & $29(48)$ & $12(42)$ & $20(30)$ & $102(33)$ \\
\hline Total & 101 (10) & 94 (22) & 117 (25) & 147 (24) & $148(28)$ & 607 (23) \\
\hline Ship ${ }^{c}$ & $3(0)$ & $1(0)$ & $1(0)$ & 0 & $3(0)$ & $8(0)$ \\
\hline Total & $104(10)$ & 95 (22) & 118 (25) & 147 (24) & $151(28)$ & $615(23)$ \\
\hline
\end{tabular}

a Accommodation sites in the European Surveillance Scheme for Travel-Associated Legionnaires' Disease (EWGLINET) scheme.

b England and Wales (together) and Scotland are independently responsible for the investigation of clusters in their respective countries. They are therefore listed separately in this table.

This category mostly comprises cruise ships, where individuals had slept in cabins onboard. 
The overall proportion of reoffences increased from $10 \%$ in 2003 to $28 \%$ in 2007 , however it should be noted that this does not necessarily reflect an increase in risk over the study period. The number of reoffenders occurring in the early years of the study may not be comparable to those occurring in the later years, since a site had to be investigated once under the European guidelines (introduced in July 2002) before a re-offence could occur. The number of reoffences occurring in the early years will therefore be artificially low.

There are several reasons why a site might reoffend. The control measures applied might have been

\section{TABLE 3}

Characteristics of European accommodation sites, including reoffending sites, investigated following clusters of Legionnaires' disease cases, 2003-2007 ${ }^{\mathrm{a}}(\mathrm{n}=477)$

\begin{tabular}{|l|r|r|r|}
\hline Characteristic & $\begin{array}{r}\text { Total number } \\
\text { of sites }\end{array}$ & $\begin{array}{r}\text { Number of } \\
\text { reoffenders }\end{array}$ & $\begin{array}{r}\text { Percentage } \\
\text { of sites } \\
\text { reoffending }\end{array}$ \\
\hline \multicolumn{4}{|l|}{ Number of rooms } \\
\hline 0-99 & 230 & 43 & 19 \\
\hline $100-199$ & 108 & 25 & 23 \\
\hline $200-299$ & 55 & 18 & 33 \\
\hline $300-399$ & 22 & 4 & 18 \\
\hline $400-499$ & 10 & 1 & 10 \\
\hline$\geq 500$ & 18 & 5 & 28 \\
\hline Not known & 34 & 4 & 12 \\
\hline Total & 477 & 100 & 21 \\
\hline Type & 25 & 6 & 24 \\
\hline $\begin{array}{l}\text { Holiday } \\
\text { apartment }\end{array}$ & 44 & 6 & 14 \\
\hline Campsite & 393 & 88 & 22 \\
\hline Hotel & 15 & 0 & 0 \\
\hline Other & 477 & 100 & 21 \\
\hline Total & & & \\
\hline
\end{tabular}

Accommodation sites in the European Surveillance Scheme for Travel-Associated Legionnaires' Disease (EWGLINET) scheme.

bvery cluster site included in dataset. Two clusters at same site included twice.

Includes ships, university halls of residence, truck stops, etc. inappropriate and/or inadequate, or there may have been a lack of long-term control measures and/or ongoing monitoring after the initial introduction of control measures. Cano et al. studied Spanish hotels and described the persistence of Legionella spp. in $29 \%$ of their reoffender accommodation sites. They concluded that there had most probably been failures in the action carried out by environmental inspectors at these sites [8]. Some countries do not have strong reference facilities for microbiological testing for Legionella spp. and may incorrectly determine that Legionella spp. cannot be detected in the water system, or the original sampling may not have been conducted properly. In these instances, negative sampling results may lead public health officials to be less stringent about control measures than they should be. There is some support for this hypothesis in the data: sites with negative sampling results were statistically more likely to reoffend than sites with positive sampling results.

Even when the initial set of control measures have been carried out correctly, the accommodation site may still reoffend if there is a change of staff and the new staff are not correctly trained in these procedures. This was one of the reasons identified for the ongoing problems experienced by a hotel in Turkey [9]. Alternatively, if an accommodation site closes over the winter period, control measures may not be reapplied as rigorously when it reopens. It is also possible that a site may reoffend despite the best efforts of public health teams, as Legionella spp. can be very difficult to eradicate from systems. It can become endemic and resist multiple rounds of chlorination and thermal disinfection, or there may be a change in the quality of the incoming water supply to an accommodation site that disrupts the system. Alternatively, the bacteria may hide in dead legs of pipework so that a site can test negative and still have Legionella spp. present in the system, which then reseeds the water system.

This analysis shows that, if the cases involved in the cluster have not stayed elsewhere during their incubation period, the likelihood of achieving at least one

\section{TABLE 4}

Investigations conducted in reoffending European accommodation sites with clusters of Legionnaires' disease cases, by sampling results, $2003-2007^{\mathrm{a}}(\mathrm{n}=132)$

\begin{tabular}{|c|c|c|c|c|c|c|c|}
\hline \multirow{2}{*}{$\begin{array}{l}\text { Sampling results (previous } \\
\text { result/reoffence result) }\end{array}$} & \multicolumn{2}{|c|}{$\begin{array}{c}\text { All cases } \\
\text { went to site only }\end{array}$} & \multicolumn{2}{|c|}{$\begin{array}{c}\text { Some cases } \\
\text { went to other sites }\end{array}$} & \multicolumn{2}{|c|}{$\begin{array}{c}\text { All cases } \\
\text { went to other sites }\end{array}$} & \multirow{2}{*}{$\begin{array}{c}\text { Total } \\
\text { number of } \\
\text { investigations }\end{array}$} \\
\hline & $\mathrm{n}$ & $\%$ & $n$ & $\%$ & $n$ & $\%$ & \\
\hline Positive/Positive & 23 & 35 & 15 & 37 & 3 & 12 & 41 \\
\hline Positive/Negative & 13 & 20 & 9 & 22 & 4 & 16 & 26 \\
\hline Negative/Positive & 16 & 24 & 7 & 17 & 7 & 28 & 30 \\
\hline Negative/Negative & 14 & 21 & 10 & 24 & 11 & 44 & 35 \\
\hline Total $^{\mathrm{b}}$ & 66 & 100 & 41 & 100 & 25 & 100 & 132 \\
\hline
\end{tabular}

a Accommodation sites in the European Surveillance Scheme for Travel-Associated Legionnaires' Disease (EWGLINET) scheme,

b Does not include three sites with unknown results on previous sampling (one tested positive and two tested negative following reoffence) and three sites that were closed and have not yet been resampled. 
positive water sample result from the accommodation site (the original investigation, the reinvestigation, or both) is higher than if all of the cases had also stayed at other sites (although the difference was not statistically significant). This could be a useful proxy for the probability of exposure at a particular cluster site, and could be used by investigators to identify cluster sites that pose a higher than normal risk.

Over $20 \%$ of sites reoffending is an unacceptably high proportion and it may be that a more extensive investigation and control regime is needed at reoffending sites. Programmes of continuous monitoring may also need to be introduced in order to better manage the risk associated with these sites.

\section{Acknowledgements}

We would like to thank Christine Campese, Didier Che, Soren Uldum and Rosa Cano Portero for their comments on this paper and the data contained therein. We would also like to thank Pia Hardelid for the statistical support and the EWGLINET collaborators for their continuing efforts in investigating clusters of travel-associated Legionnaires' disease across Europe.

\section{References}

1. Bartram J, Chartier Y, Lee, JV, Pond K, Surman-Lee S, editors. Legionella and the prevention of legionellosis. Geneva: World Health Organization; 2007.

2. Federation of Tour Operators (FTO). Preferred codes of practice. Health and safety. London: FTO. [Accessed 6 October 2010]. Available from: http://www.fto.co.uk/health-and-safety/ preferred-code-of-practice/

3. European Centre for Disease Prevention and Control (ECDC). European Legionnaires' Disease Surveillance Network (ELDSNet). Stockholm: ECDC. [Accessed 6 October 2010]. Available from: http://ecdc.europa.eu/en/activities/ surveillance/ELDSNet/Pages/Index.aspx

4. European Working Group for Legionella Infections. European guidelines for control and prevention of travel associated Legionnaires' disease. London: PHLS; 2002.

5. Available from: http://www.hpa.org.uk/web/HPAwebFile/ HPAweb_C/1274093149925

6. Joseph, C. European surveillance of travel associated Legionnaires' disease. Euro Surveill. 2004;9(2). pii: 443. Available from: http://www.eurosurveillance.org/ViewArticle. aspx?Articleld $=443$

7. Ricketts K, Joseph C. Travel associated Legionnaires' disease in Europe: 2003. Euro Surveill. 2004;9(10). pii: 480. Available from: http://www.eurosurveillance.org/ViewArticle. aspx?Articleld $=480$

8. Joseph CA, Yadav R, Ricketts KD, on behalf of the European Working Group for Legionella Infections. Travel-associated Legionnaires' disease in Europe in 2007. Euro Surveill. 2009;14(18). pii: 19196. Available from:

9. http://www.eurosurveillance.org/ViewArticle. aspx?Articleld $=19196$

10. Cano R, Nogareda F, Baladron B, Martin C, Pelaz C. Description of clusters of Legionnaires' disease associated with Spanish reoffender accommodation sites in the period 1987 to 2009 . Legionella 2009 conference, 13-17 Oct 2009, Institut Pasteur, Paris, France. Abstract book, p. 285.

11. Cluster of cases of Legionnaires' disease associated with travel to Turkey. Commun Dis Rep CDR Wkly. 1996;6(41):355 